\title{
Review
}

Acta Haematol 2013;129:207-214

DOI: $\underline{10.1159 / 000345260}$
Received: May 7, 2012

Accepted after revision: October 3, 2012

Published online: January 3, 2013

\section{Recent Advancements of Bortezomib in Acute Lymphocytic Leukemia Treatment}

\author{
Xiao-Li Du Qi Chen \\ Department of Hematology, The Affiliated Hospital of Zunyi Medical College, Zunyi, China
}

\section{Key Words}

Acute lymphoblastic leukemia $\cdot$ Bortezomib $\cdot$ Molecular mechanism

\begin{abstract}
Although survival rates for acute lymphocytic leukemia (ALL), especially in children, have shown dramatic improvement over time, poor outcomes are still observed in patients who have refractory or relapsed disease after conventional chemotherapy. New therapeutic options are urgently needed. Bortezomib (Velcade, formerly PS-341) is the first proteasome inhibitor approved by the US FDA for the treatment of newly diagnosed multiple myeloma and relapsed/refractory multiple myeloma and mantle cell lymphoma. Although the mechanisms of bortezomib anticancer activity are still not completely understood, it is a new treatment option for patients with refractory or relapsed ALL, particularly when used in combination with conventional chemotherapy or targeted agents. This review summarizes recent advancements in the understanding of the bortezomib molecular mechanism of action in ALL. Understanding of the molecular approaches might help customize cancer chemotherapy for each individual patient, directing the field towards rational therapeutics.

Copyright $\odot 2013$ S. Karger AG, Basel
\end{abstract}

\section{Introduction}

\section{Pathobiology of Acute Lymphocytic Leukemia}

Acute lymphocytic leukemia (ALL) is a malignant disorder that originates from one single hematopoietic precursor committed to the B cell or T cell lineage; $80-85 \%$ of ALL are of B-cell lineage (B cell precursor ALL, BCPALL) and $15-20 \%$ are of T cell lineage (T-ALL). Although the exact mechanisms leading to malignant transformation are unknown, chromosomal translocations, recurrent cytogenetic abnormalities and disrupting key signaling pathways may lead to leukemogenesis following a multistep process [1]. Table 1 summarizes the most frequent abnormalities observed in B-ALL and T-ALL [1]. Better comprehension of genetic alterations of ALL cells will provide the molecular rationales for improving prognostic stratification and selecting new therapeutic targets.

\section{Management Strategies in ALL}

ALL is the most common pediatric malignancy [2]. There is a second peak of incidence in the elderly population [3]. Survival rates for ALL, especially in children, have shown dramatic improvement over time due to the recognition of the biologic heterogeneity of ALL, the uti-

\section{KARGER \\ Fax +4161306 1234 \\ E-Mail karger@karger.ch}

www.karger.com (c) 2013 S. Karger AG, Basel

0001-5792/13/1294-0207\$38.00/0

Accessible online at:

www.karger.com/aha
Qi Chen, MD

Department of Hematology

The Affiliated Hospital of Zunyi Medical College

Zunyi, Guizhou 563003 (China)

E-Mail chenqizys@163.com 
Table 1. Most frequent genetic abnormalities in ALL

\begin{tabular}{|c|c|c|}
\hline (Cyto)genetic changes & Genes & Remarks/prognosis \\
\hline \multicolumn{3}{|l|}{$B C P-A L L$} \\
\hline \multicolumn{3}{|l|}{ Ig receptor gene translocations } \\
\hline $\mathrm{t}(8 ; 14)(\mathrm{q} 11 ; \mathrm{q} 32)$ & CEBPD;IGH & \\
\hline $\mathrm{t}(14 ; 19)(\mathrm{q} 32 ; \mathrm{p} 13)$ & IGH;EPOR & \\
\hline $\mathrm{t}(\mathrm{X}, 14)(\mathrm{p} 22 ; \mathrm{q} 32)$ & CRLF2;IGH & \\
\hline $\mathrm{t}(6 ; 14)(\mathrm{p} 21 ; \mathrm{q} 32)$ & ID4;IHG & \\
\hline \multicolumn{3}{|l|}{ Fusion genes } \\
\hline $\mathrm{t}(12 ; 21)(\mathrm{p} 13 ; \mathrm{q} 22)$ & ETV6-RUNX1 & Childhood, favorable \\
\hline $\mathrm{t}(9 ; 22)(\mathrm{q} 34 ; \mathrm{q} 21)$ & BCR-ABL1 & Adult, poor \\
\hline $\mathrm{t}(1 ; 19)(\mathrm{q} 23 ; \mathrm{p} 13)$ & E2A-PBX1 & \\
\hline $\mathrm{t}(4 ; 11)(\mathrm{q} 21 ; \mathrm{q} 23)$ & MLL-AF4 & Infant, very poor \\
\hline $\mathrm{t}(9 ; 11)(\mathrm{p} 22 ; \mathrm{q} 23)$ & MLL-AF9 & \\
\hline $\mathrm{t}(11 ; 19)(\mathrm{q} 23 ; \mathrm{p} 13)$ & MLL-ENL & \\
\hline $\operatorname{del}(\mathrm{X}) / \operatorname{del}(\mathrm{Y})$ & P2RY8-CRLF2 & \\
\hline \multicolumn{3}{|l|}{ Deletion } \\
\hline $\operatorname{del}(9)(\mathrm{p} 21)$ & CDKN2A & \\
\hline \multicolumn{3}{|l|}{ Ploidy changes } \\
\hline High hyperdiploid (>50 chromosomes) & & Childhood, favorable \\
\hline Hypodiploid (<45 chromosomes) & & Very poor \\
\hline Mutations & PAX5, IKZF1, EBF1 & \\
\hline \multicolumn{3}{|l|}{$T-A L L$} \\
\hline \multicolumn{3}{|l|}{ TCR receptor gene translocations (14q11 and 7q34) } \\
\hline $\mathrm{t}(10 ; 14)(\mathrm{q} 24 ; \mathrm{q} 11)$ & TLX1;TCRA/D & Favorable \\
\hline $\mathrm{t}(11 ; 14)(\mathrm{p} 15 ; \mathrm{q} 11)$ & LMO1;TCR & \\
\hline $\mathrm{t}(11 ; 14)(\mathrm{p} 13 ; \mathrm{q} 11)$ & LMO2;TCR & \\
\hline $\mathrm{t}(1 ; 14)(\mathrm{p} 32 ; \mathrm{q} 11)$ & TAL1;TCR & \\
\hline $\operatorname{inv}(7)(\mathrm{p} 15 \mathrm{q} 32)$ & HOXA;TCRB & \\
\hline $\mathrm{t}(7 ; 19)(\mathrm{q} 34 ; \mathrm{p} 13)$ & LYL1;TCRB & \\
\hline $\mathrm{t}(5 ; 14)(\mathrm{q} 35 ; \mathrm{q} 32)$ & TLX3;BCL11B & Poor? \\
\hline \multicolumn{3}{|l|}{ Fusion genes } \\
\hline del1(p32) interstitial & SIL-TAL1 & \\
\hline $9(q 34)$ episomes & NUP214-ABL1 & \\
\hline $\mathrm{t}(10 ; 11)(\mathrm{p} 13 ; \mathrm{q} 14)$ & CALM-AF10 & \\
\hline $\mathrm{t}(11 ; 19)(\mathrm{q} 23 ; \mathrm{p} 13)$ & MLL-ENL & \\
\hline \multicolumn{3}{|l|}{ Deletion/amplification } \\
\hline $\operatorname{del}(9)(\mathrm{p} 21)$ & CDKN2A & \\
\hline $\operatorname{del}(6 q)$ & Unknown & \\
\hline $\operatorname{dup}(6)(q 23)$ & MYB & \\
\hline \multirow[t]{2}{*}{ Mutations } & NOTCH1/FBW7 & Very frequent $(>80 \%)$ \\
\hline & JAK1, PTEN, RAS, FLT3, PHF6 & \\
\hline
\end{tabular}

lization of risk-adapted therapy, the development of protocols that include optimized chemotherapy combinations, the postinduction intensification of therapy, effective central nervous system prophylaxis and a prolonged maintenance phase of treatment. Previous published reports have suggested childhood ALL has secured 5-year event-free survival rates of approximately $80 \%$ and 5 -year survival rates approaching $90 \%[3,4]$. The 5 -year survival rates of adult ALL are in the region of $50 \%$ [5].
The first step in the case of a preliminary diagnosis of ALL is induction therapy. The goal of induction therapy is the eradication of ALL cells in as many patients, as early, and with as few toxic adverse effects as possible. Generally, induction regimens consist of asparaginase (Elspar), vincristine, a glucocorticoid, and in some cases an anthracycline, for a period of 4-6 weeks. Complete remission (CR) is achieved in approximately $98 \%$ of children and $85 \%$ of adults $[3,5]$. To consolidate remission 
status, further intensification of therapy following induction is necessary. Most current programs employ 6-8 courses, 2-4 of which contain 1 of high-dose methotrexate, cytarabine and asparaginase [6-8]. In addition to reduction of systemic disease burden, another key goal of postinduction therapy is the prevention of central nervous system disease. Postremission consolidation is most often followed by long-term maintenance with daily oral mercaptopurine and weekly methotrexate for 2 years or longer, sometimes with periodic reinforcements (e.g. vincristine, prednisone and other drugs). In this regard, for a subset of very high-risk childhood ALL cases, such as those that involve induction failure, severe hypodiploidy, the Philadelphia $(\mathrm{Ph})$ chromosome and high leukocyte count in those patients with a poor response to initial therapy, hematopoietic stem-cell transplantation is a sensible option in first remission.

Although impressive improvements in outcome have been made in ALL, relapsed ALL remains the fourth most common pediatric malignancy [9]. Intensive conventional chemotherapy can achieve second remission (CR2).

Further chemotherapy and hematopoietic stem-cell transplantation are two CR2 therapeutic options. For patients in refractory first relapse or second or subsequent relapse, several drug combinations, such as ifosfamide and etoposide, high-dose cytarabine and L-asparaginase have reported complete response rates of around 40\% [9]. Nevertheless, significant challenges remain. Poor outcomes are still observed in patients who have refractory or relapsed disease $[10,11]$. New therapeutic options are urgently needed. Currently, several new methods for relapsed ALL have been advancing in clinical trials $[3,9]$ including deoxyadenosine analogs (clofarabine and nelarabine), monoclonal antibodies (alemtuzumab and epratuzumab) and the proteasome inhibitor bortezomib.

\section{Proteasome Inhibitor: Bortezomib}

Resistance to standard chemotherapy regimens is an expanding problem in the treatment of cancer. Research into novel targeted therapeutics either alone or in combination with existing agents used in the clinic has shown significant potential. Proteasome inhibitors constitute a growing group of compounds currently under clinical use or investigation.

\section{Possible Mechanisms}

Bortezomib (Velcade, formerly PS-341) is the first proteasome inhibitor approved by the US FDA for the treat- ment of newly diagnosed multiple myeloma (MM) and relapsed/refractory MM and mantle cell lymphoma [12, 13]. Despite the fact that the anticancer activity of bortezomib is still not completely understood, it is clear that multiple mechanisms are involved. The key proteins and signaling pathways affected and subsequent cellular effects are summarized in figure 1 [14].

\section{Adverse Effects}

The most frequent side effects of bortezomib in clinical trials include asthenic conditions (such as fatigue, weakness and malaise), gastrointestinal events (nausea, diarrhea, vomiting or constipation), thrombocytopenia, peripheral neuropathy, pyrexia and psychiatric disorders [15]. During phase I clinical trials for bortezomib in human patients with cancer, dose-limiting toxicities included sensory neuropathy, diarrhea, fatigue, hypotension, fluid retention, hypokalemia, hyponatremia, malaise, nausea, orthostasis and thrombocytopenia [16]. In general, the combination of bortezomib with other chemotherapeutic agents resulted in a tolerability profile that was consistent with those of the individual agents involved and did not result in any unexpected adverse events [15], so combining bortezomib with other agents may be superior to single drugs in treatment.

\section{Combination Studies}

Combination therapy of bortezomib with novel targeted agents is an emerging treatment strategy not only in MM and mantle cell lymphoma, but also in leukemia [14]. A phase I study by Attar et al. [17] suggested that bortezomib is well tolerated in combination with idarubicin and cytarabine in acute myelogenous leukemia (AML). Recently, a combination with bortezomib and valproic acid (a histone deacetylase inhibitor) was reported with very promising activity for AML in vitro $[18,19]$. In addition, the Therapeutic Advances in Childhood Leukemia (TACL) phase I and II studies showed that a combination of bortezomib with chemotherapy is active with acceptable toxicity in ALL $[20,21]$. These findings indicate that most of these combinations are well tolerated and some have promising clinical efficacy that will require subsequent confirmation.

\section{Bortezomib in ALL}

Initial activity with bortezomib in ALL was observed in a child with multiple relapse. The patient, who had experienced 5 relapses including 1 after an unrelated-donor 
Fig. 1. The intracellular pathways and proteins affected by proteasome inhibition with bortezomib. Ros = Reactive oxygen species; JNK = c-Jun N-terminal kinase.

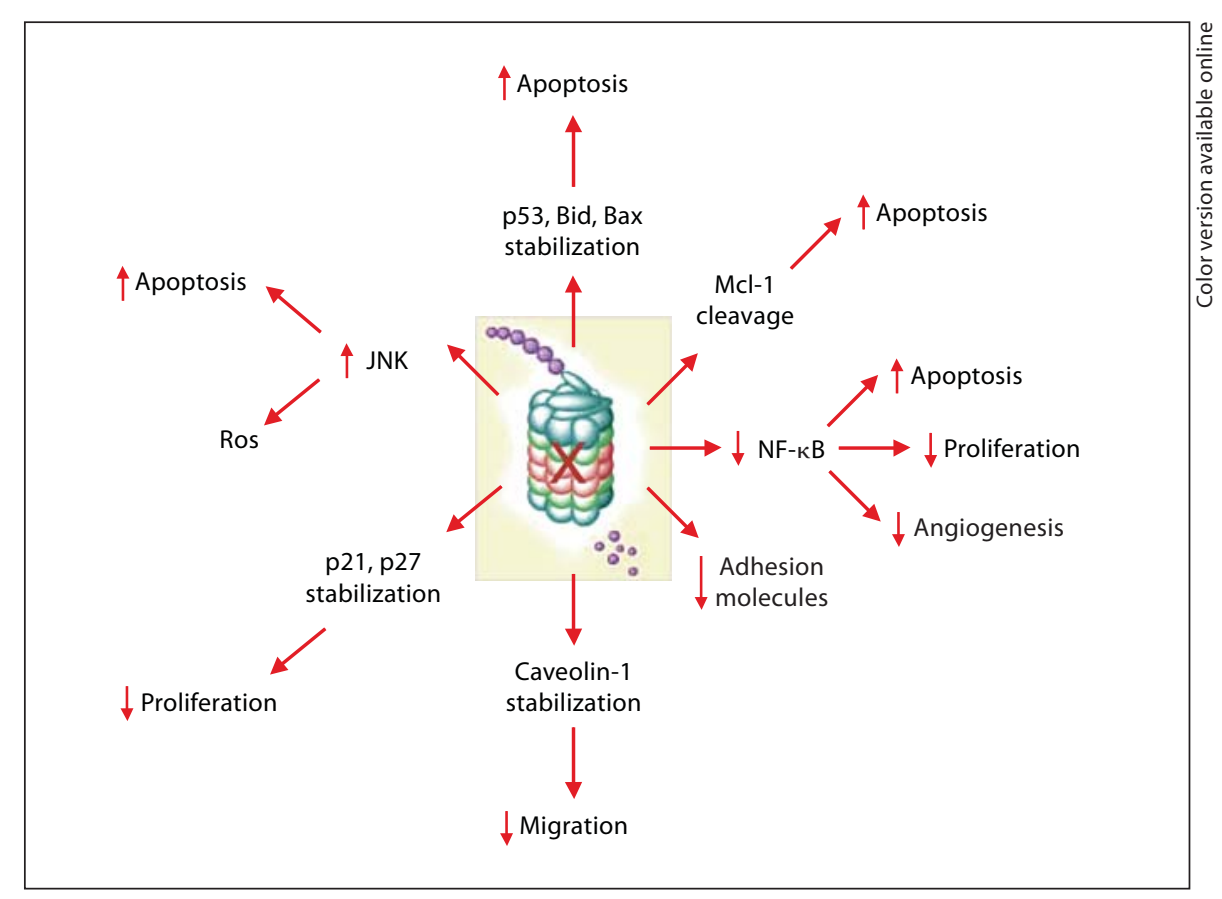

bone marrow transplant, was resistant to dexamethasone and most standard antileukemic agents, and NF- $\mathrm{B}$ was activated in his leukemia cells. After treatment with bortezomib at a dose of $1.2 \mathrm{mg} / \mathrm{m}^{2}$ i.v. on days $1,4,8$ and 11 , followed by dexamethasone therapy $6 \mathrm{mg} / \mathrm{m}^{2} /$ day on days $4-15$, the patient's CT scans showed a significant decrease of tumor size in the skull, chest wall, renal and hepatic lesions [22]. This promising response led to further investigation.

Although other clinical studies show very little activity of the single agent bortezomib in either adults [23] or children [24] with acute leukemia, the study by Houghton et al. [25] did show some activity of single-agent bortezomib for pediatric ALL in preclinical models. Bortezomib may have enhanced antileukemic activity when used in combination with chemotherapy or targeted agents. In a phase-I study, the TACL consortium reported that the combination of bortezomib $\left(1.3 \mathrm{mg} / \mathrm{m}^{2}\right)$ with vincristine, dexamethasone, pegylated L-asparaginase and doxorubicin is active with acceptable toxicity in pretreated pediatric patients with relapsed ALL [20], consistent with their phase II study [21]. Recently, a phase I clinical pharmacodynamic study by Lancet et al. [26] also reported combination therapy with bortezomib and the farnesyltransferase inhibitor tipifarnib is well tolerated and produces modest antileukemic clinical activity in patients with advanced, poor-risk acute leukemia, including ALL.
The consistent degree of activity noted in these studies demonstrates that bortezomib is an important new treatment option for patients with relapsed ALL, particularly when used in combination with other agents. However, the mechanisms of bortezomib anticancer activity are still unclear. Possible pathways are reviewed below.

\section{Inhibition of Notch1-NFкB Signaling Pathway in}

T-ALL

Of great importance, aberrant NF- $\kappa \mathrm{B}$ regulation has been observed in many cancers, including both solid and hematopoietic malignancies [27]. Indeed, Kordes et al. [28] observed NF- $\kappa$ B activity in 39 of 42 samples of childhood ALL without any subtype restriction. In addition, the study by Guzman et al. [29] demonstrated that human AML stem cells also express an active form of NF- $\kappa$ B. Expression of NF- $\mathrm{KB}$ in both AML and ALL cells represents a striking biologic distinction between leukemic and normal tissue $[28,29]$. Taken together, these results indicate that NF- $\kappa$ B plays a critical role in the survival of leukemia cells including leukemic stem cells.

Previous studies have reported that bortezomib can overcome chemoresistance and restore sensitivity to specific agents, including doxorubicin, melphalan and dexamethasone, and suggested that a possible mechanism for the chemosensitizing activity of bortezomib is the ability of NF- $\kappa \mathrm{B}$ to promote resistance to these agents in MM 
cell lines [30]. In addition, a patient of T-ALL, who was resistant to conventional chemotherapy, achieved second remission following treatment with a combination of bortezomib, dexamethasone and doxorubicin, and the binding activity of NF- $\mathrm{\kappa B}$-DNA in his bone marrow was strikingly reduced [31]. This is similar to the initial activity with bortezomib in ALL [22]. Therefore, NF- $\kappa$ B has the potential to cause resistance to agents including glucocorticoids.

Inhibiting NF- $\kappa \mathrm{B}$ activation is one of the potential mechanisms of bortezomib [14]. The results of in vitro individualized tumor response testing showed that bortezomib is more active in pediatric T-ALL samples than in common/pre-B-ALL pediatric samples. A possible explanation for these findings is that the NF- $\mathrm{KB}$ pathway is present in a high proportion of T-ALL samples, but not in BCP-ALL samples [32]. However, it is not completely consistent with the study of Kordes et al. [28] discussed above. Bortezomib and other NF- $\mathrm{\kappa B}$-inhibiting agents are, nevertheless, attractive candidates for T-ALL treatment.

Previous reports have demonstrated that activating mutations in Notch 1 are present in most individuals with human T-ALL [33] and in mouse models of T-ALL [34]. The Notch1 signaling pathway plays a critical role in promoting many steps of $\mathrm{T}$ cell development and aberrant Notchl signaling is a major oncogenic event in the pathogenesis of T-ALL [35]. These findings provide a strong rationale for targeted therapies that interfere with Notch1 signaling in human T-ALL.

The Notch1 signaling pathway, commonly activated in T-ALL, has been shown to enhance the transcriptional function of NF- $\kappa B$ via several mechanisms.

Previous reports have proposed that Notch-1 could activate the NF- $\kappa \mathrm{B}$ canonical signaling by facilitating the nuclear retention of NF- $\kappa B$ heterodimers [36], activating the IкB kinase complex, and the noncanonical pathway by inducing the expression of the NF- $\kappa \mathrm{B}$ factors Relb and Nfkb2 [37]. Very recent work has demonstrated that the transcriptional repressor HES1, a target of oncogenic Notch1, is able to induce the activation of the NF- $\mathrm{BB}$ pathway through CYLD (a negative IкB kinase complex regulator) repression in human T-ALL lines and in animal models of the disease [38]. However, NF- $\kappa \mathrm{B}$ is not sufficient to give rise to $\mathrm{T}$ cell leukemia in the absence of activating Notch1 mutations [37]. It has been suggested that the pharmacological inhibition of Notch1-NFкB signaling be incorporated into existing T-ALL treatment protocols. Combining bortezomib with Notch1-inhibiting agents may be more therapeutically beneficial than single drugs.
Restoration of Expression of FoxO3 for $\mathrm{Ph}$

\section{Chromosome-Positive ALL Patients}

The $\mathrm{Ph}$ chromosome results from a reciprocal translocation between chromosomes 9 and 22 ( $t[9,22]$ [q34; q11]), which produces a fusion gene on chromosome 22 , namely, the breakpoint cluster region-Abelson leukemia viral proto-oncogene (BCR-ABL). Approximately one quarter of adult ALL expresses the oncogenic protein BCR-ABL [39]; however, it occurs in only $3-5 \%$ of pediatric cases [40]. Recently, Ph chromosome-positive ALL children and adolescents are considered one of the poor-risk subgroups of ALL patients. As a result of its elevated tyrosine kinase activity, BCR-ABL activates a multitude of signaling pathways, including the Ras, PI3K/Akt, JAK/STAT and NF- $\mathrm{B}$ signaling pathways, some of which may be crucial for its leukemogenic activity [41].

Recent studies have revealed that the inhibition of FoxO (Forkhead Box, class O) function is a potentially important event, even in hematological malignancies. The mammalian members of the FoxO subclass include FoxO1 (also known as FKHR), FoxO3a (also known as FKHRL1), FoxO4 (also known as AFX) and FoxO6. The functions of FoxO3a transcription factor in cell cycle arrest and apoptosis occur through the transcriptional regulation genes such as cyclin D, TRAIL and Bim, and survival signaling through the PI3-K/Akt pathway prevents FoxO3a transcriptional activity [41].

The study by Jagani et al. [42] proposed that BCR-ABL stimulates the proteasome-dependent degradation of members of the forkhead family of tumor suppressors in vitro, in an in vivo animal model and in samples from patients with BCR-ABL-positive chronic myelogenous leukemia or ALL. Bortezomib treatment of BCR-ABLtransduced leukemic mice restored normal expression of FoxO3a and its targets TRAIL and Bim [42]. Their study also reported that FoxO3 is significantly downregulated within lymphoblasts of Ph-positive ALL, but not Ph-negative ALL, and the Ph-positive ALL patient who was treated with bortezomib achieved full molecular and cytogenetic remission and restoration of expression of FoxO3 in response to the drug [43]. These results support the fact that FoxO3 is attenuated in BCR-ABL-mediated disease and may be utilized as a potential diagnostic biomarker. Bortezomib treatment led to the inhibition of BCR-ABL-induced suppression of FoxO proteins and their proapoptotic targets, thereby providing novel insights into the molecular effects of proteasome inhibitor therapy (fig. 2). 
Fig. 2. Bortezomib treatment led to inhibition of BCR-ABL-induced suppression of FoxO proteins and their proapoptotic targets in $\mathrm{Ph}+\mathrm{ALL}$ patients.

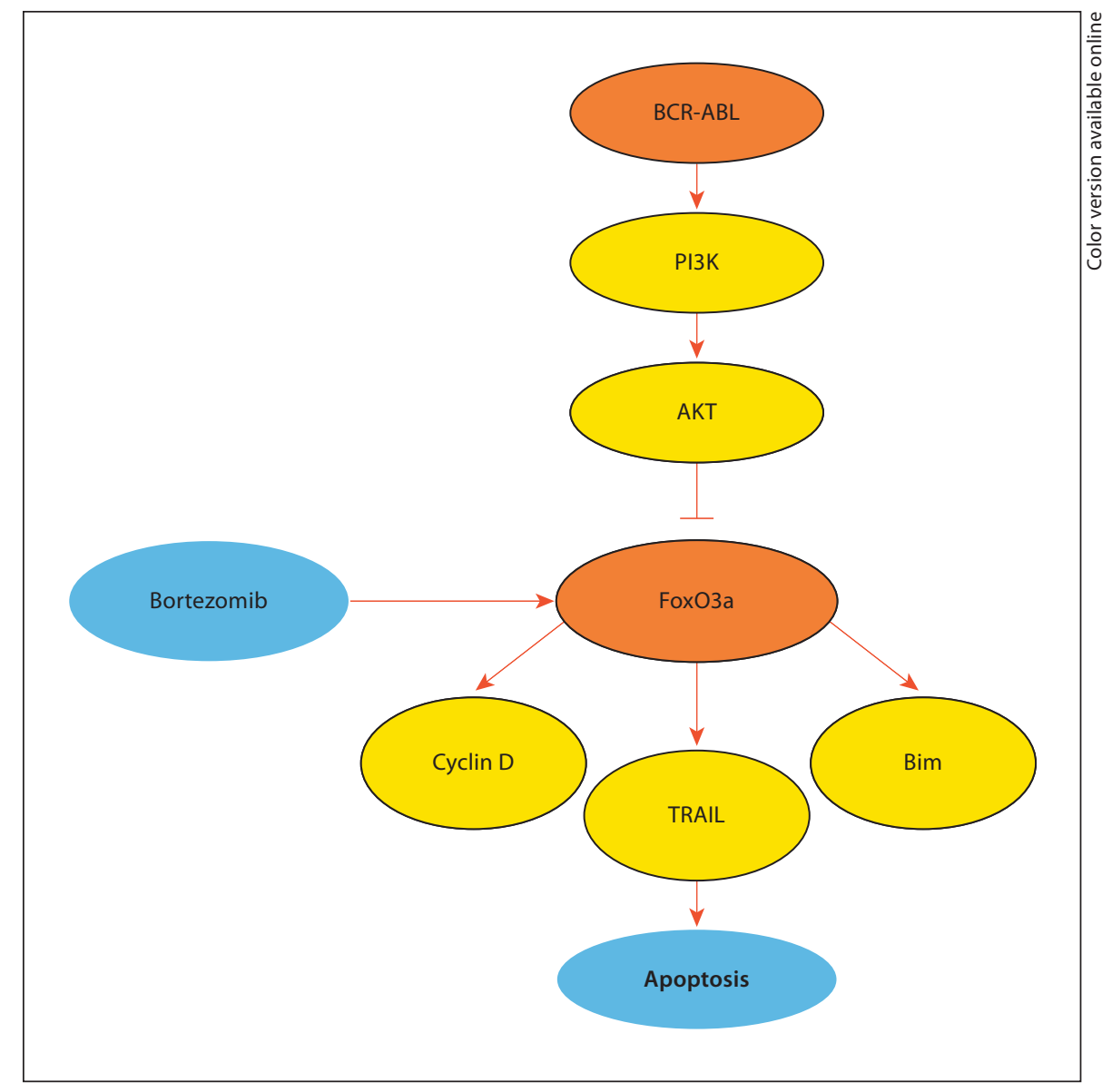

\section{Activation of JNK Signaling Pathways}

A number of new agents, including proteasome inhibitors, initiate apoptosis through the activation of mitogen-activated protein kinase pathways including the Jun $\mathrm{N}$-terminal kinase (JNK) pathway [44]. JNK is a member of the mitogen-activated protein kinase superfamily. It has three isoforms, JNK 1, 2 and 3, of which JNK 1 and 2 are ubiquitously expressed but JNK 3 specifically in the cardiac and neuronal tissues [45]. Recent studies have demonstrated that JNK activation can contribute to apoptosis induced by certain death stimuli [46]. The synergistic effect of proteasome inhibitor bortezomib and other agents, such as valproic acid [18], all-trans retinoic acid [47] and HA14-1 (a small molecule antagonist of the antiapoptotic proteins) [48] were investigated in a variety of cancer cells in association with JNK activation.

In ALL cell lines, JNK signaling played an important part in the mechanism of synergy of cytotoxic retinoid $\mathrm{N}$-(4-hydroxyphenyl)retinamide (4-HPR) and the Bcl-2 inhibitor ABT-737, 4-HPR is known to generate reactive oxygen species which have been shown to activate c-Jun kinase (JNK), which in turn phosphorylates and inhibits myeloid cell leukemia 1 (Mcl-1), an antiapoptotic member of the Bcl-2 family of proteins [49]. The synergy between the mammalian target of rapamycin inhibitor RAD001 (everolimus) and bortezomib indicated a potentially novel strategy for patients with chemoresistant preB-ALL; bortezomib potently induced JNK activation with a significant proportion of subsequent cell death being JNK-dependent [50]. In summary, combination therapy of bortezomib and novel targeted agents is an emerging treatment strategy in cancer.

\section{Conclusions and Future Perspective}

The outcomes of refractory or relapsed ALL are still dismal. Although there are not many clinical studies of proteasome inhibitors with bortezomib in ALL, bortezomib is a new treatment option for these refractory or re- 
lapsed patients. Combination therapy with bortezomib and other agents, including conventional chemotherapy and targeted agents, may be more efficacious than single drugs in ALL. We need more in vitro and in vivo study in order to understand the mechanisms of bortezomib as a new agent in ALL. The integration of bortezomib with other regimens has still to be defined, underlining a much-needed effort to enroll ALL patients in clinical trials. The understanding of molecular approaches might help guide our treatment decisions and move the field towards more rational therapeutics, hopefully improving patient outcome as well as illustrating the changing paradigm of this disease.

\section{References}

1 Graux C: Biology of acute lymphoblastic leukemia (ALL): clinical and therapeutic relevance. Transfus Apher Sci 2011;44:183-189.

2 United States Cancer Statistics: 1999-2005 Incidence and Mortality Web-based Report. Atlanta, US Department of Health and $\mathrm{Hu}-$ man Services, Centers for Disease Control and Prevention and National Cancer Institute, 2009. http:// www.cdc.gov/uscs (accessed May 28, 2010).

-3 Pui CH, Evans WE: Treatment of acute lymphoblastic leukemia. N Engl J Med 2006;354: 166-178.

4 Pui CH: Recent research advances in childhood acute lymphoblastic leukemia. J Formos Med Assoc 2010;109:777-787.

$>5$ Gökbuget N, Hoelzer D: Treatment of adult acute lymphoblastic leukemia. Semin Hematol 2009;46:64-75.

6 Pui CH, Pei D, Sandlund JT, Ribeiro RC, Rubnitz JE, Raimondi SC, Onciu M, Campana D, Kun LE, Jeha S, Cheng C, Howard SC, Metzger ML, Bhojwani D, Downing JR, Evans WE, Relling MV: Long-term results of St Jude Total Therapy Studies 11, 12, 13A, $13 \mathrm{~B}$, and 14 for childhood acute lymphoblastic leukemia. Leukemia 2010;24:371-382.

-7 Möricke A, Reiter A, Zimmermann M, Gadner H, Stanulla M, Dördelmann M, Löning L, Beier R, Ludwig WD, Ratei R, Harbott J,Boos J, Mann G, Niggli F, Feldges A, Henze G, Welte K, Beck JD, Klingebiel T, Niemeyer C, Zintl F, Bode U, Urban C, Wehinger $\mathrm{H}$, Niethammer D, Riehm H, Schrappe M: Riskadjusted therapy of acute lymphoblastic leukemia can decrease treatment burden and improve survival: treatment results of 2,169 unselected pediatric and adolescent patients enrolled in the trial ALL-BFM 95. Blood 2008;111:4477-4489.

$>8$ Moghrabi A, Levy DE, Asselin B, Barr R, Clavell L, Hurwitz C, Samson Y, Schorin M, Dalton VK, Lipshultz SE, Neuberg DS, Gelber RD, Cohen HJ, Sallan SE, Silverman LB: Results of the Dana-Farber Cancer Institute ALL Consortium Protocol 95-01 for children with acute lymphoblastic leukemia. Blood 2007; 109:896-904.
9 Harned TM, Gaynon PS: Relapsed acute lymphoblastic leukemia: current status and future opportunities. Curr Oncol Rep 2008; 10:453-458.

10 Fielding AK, Richards SM, Chopra R, Lazarus HM, Litzow MR, Buck G, Durrant IJ, Luger SM, Marks DI, Franklin IM, McMillan AK, Tallman MS, Rowe JM, Goldstone $\mathrm{AH}$ : Outcome of 609 adults after relapse of acute lymphoblastic leukemia (ALL); an MRC UKALL12/ECOG 2993 study. Blood 2007;109:944-950.

-11 Ko RH, Ji L, Barnette P, Bostrom B, Hutchinson R, Raetz E, Seibel NL, Twist CJ, Eckroth E, Sposto R, Gaynon PS, Loh ML: Outcome of patients treated for relapsed or refractory acute lymphoblastic leukemia: therapeutic advances in childhood leukemia consortium study. J Clin Oncol 2010;28:648-654.

12 Kane RC, Bross PF, Farrell AT, Pazdur R: Velcade: U.S. FDA approval for the treatment of multiple myeloma progressing on prior therapy. Oncologist 2003;8:508-513.

13 Kane RC, Dagher R, Farrell A, Ko CW, Sridhara R, Justice R, Pazdur R: Bortezomib for the treatment of mantle cell lymphoma. Clin Cancer Res 2007;13:5291-5294.

14 Wright JJ: Combination therapy of bortezomib with novel targeted agents: an emerging treatment strategy. Clin Cancer Res 2010;16: 4094-4104.

15 Curran MP, McKeage K: Bortezomib: a review of its use in patients with multiple myeloma. Drugs 2009;69:859-888.

16 Cvek B: Proteasome inhibitors. Prog Mol Biol Transl Sci 2012;109:161-226.

17 Attar EC, De Angelo DJ, Supko JG, D’Amato F, Zahrieh D, Sirulnik A, Wadleigh M, Ballen KK, McAfee S, Miller KB, Levine J, Galinsky I, Trehu EG, Schenkein D, Neuberg D, Stone RM, Amrein PC: Phase I and pharmacokinetic study of bortezomib in combination with idarubicin and cytarabine in patients with acute myelogenous leukemia. Clin Cancer Res 2008;14:1446-1454.

-18 Wang AH, Wei L, Chen L, Zhao SQ, Wu WL, Shen ZX, Li JM: Synergistic effect of bortezomib and valproic acid treatment on the proliferation and apoptosis of acute myeloid leukemia and myelodysplastic syndrome cells. Ann Hematol 2011;90:917-931.
19 Nie D, Huang K, Yin S, Li Y, Xie S, Ma L, Wang X, Wu Y, Xiao J: Synergistic/additive interaction of valproic acid with bortezomib on proliferation and apoptosis of acute myeloid leukemia cells. Leuk Lymphoma 2012; 53:2487-2495.

20 Messinger Y, Gaynon P, Raetz E, Hutchinson R, Dubois S, Glade-Bender J, Sposto R, van der Giessen J, Eckroth E, Bostrom BC: Phase I study of bortezomib combined with chemotherapy in children with relapsed childhood acute lymphoblastic leukemia (ALL): a report from the therapeutic advances in childhood leukemia (TACL) consortium. Pediatr Blood Cancer 2010;55:254259.

21 Messinger YH, Gaynon PS, Sposto R, van der Giessen J, Eckroth E, Malvar J, Bostrom BC: Bortezomib with chemotherapy is highly active in advanced B-precursor acute lymphoblastic leukemia: therapeutic advances in childhood leukemia lymphoma (TACL) study. Blood 2012;120:285-290.

22 Brown RE, Bostrom B, Zhang PL: Morphoproteomics and bortezomib/dexamethasone-induced response in relapsed acute lymphoblastic leukemia. Ann Clin Lab Sci 2004;34:203-205.

23 Cortes J, Thomas D, Koller C, Giles F, Estey E, Faderl S, Garcia-Manero G, McConkey D, Ruiz SL, Guerciolini R, Wright J, Kantarjian $\mathrm{H}$ : Phase I study of bortezomib in refractory or relapsed acute leukemias. Clin Cancer Res 2004; 10:3371-3376.

24 Horton TM, Pati D, Plon SE, Thompson PA, Bomgaars LR, Adamson PC, Ingle AM, Wright J, Brockman AH, Paton M, Blaney SM: A phase 1 study of the proteasome inhibitor bortezomib in pediatric patients with refractory leukemia: a children's oncology group study. Clin Cancer Res 2007;13:15161522 .

25 Houghton PJ, Morton CL, Kolb EA, Lock R, Carol H, Reynolds CP, Keshelava N, Maris JM, Keir ST, Wu J, Smith MA: Initial testing (stage 1) of the proteasome inhibitor bortezomib by the pediatric preclinical testing program. Pediatr Blood Cancer 2008;50:3745. 
26 Lancet JE, Duong VH, Winton EF, Stuart RK, Burton M, Zhang S, Cubitt C, Blaskovich MA, Wright JJ, Sebti S, Sullivan DM: A phase I clinical-pharmacodynamic study of the farnesyltransferase inhibitor tipifarnib in combination with the proteasome inhibitor bortezomib in advanced acute leukemias. Clin Cancer Res 2011;17:1140-1146.

27 Luqman S, Pezzuto JM: NFkappaB: a promising target for natural products in cancer chemoprevention. Phytother Res 2010;24: 949-963.

28 Kordes U, Krappmann D, Heissmeyer V, Ludwig WD, Scheidereit C: Transcription factor NF- $\kappa \mathrm{B}$ is constitutively activated in acute lymphoblastic leukemia cells. Leukemia 2000;14:399-402.

-29 Guzman ML, Neering SJ, Upchurch D, Grimes B, Howard DS, Rizzieri DA, Luger $\mathrm{SM}$, Jordan CT: Nuclear factor- $\mathrm{\kappa} B$ is constitutively activated in primitive human acute myelogenous leukemia cells. Blood 2001;98: 2301-2307.

- 30 Mitsiades N, Mitsiades CS, Richardson PG, Poulaki V, Tai YT, Chauhan D, Fanourakis G, Gu X, Bailey C, Joseph M, Libermann TA, Schlossman R, Munshi NC, Hideshima T, Anderson KC: The proteasome inhibitor PS341 potentiates sensitivity of multiple myeloma cells to conventional chemotherapeutic agents: therapeutic applications. Blood 2003; 101:2377-2380.

- $31 \mathrm{Xu}$ JJ, Hu XH, Shen YY, Sun AN, Guo F, He GS: Clinical analysis of bortezomib combined with chemotherapy for one case of refractory acute lymphocytic leukemia. Zhonghua Xue Ye Xue Za Zhi 2011;32:697-698.

-32 Szczepanek J, Pogorzala M, Konatkowska B, Juraszewska E, Badowska W, Olejnik I, Kuzmicz M, Stanczak E, Malinowska I,Stefaniak J, Sobol G, Szczepanski T, Czyzewski K, Wysocki M, Styczynski J: Differential ex vivo activity of bortezomib in newly diagnosed paediatric acute lymphoblastic and myeloblastic leukaemia. Anticancer Res 2010;30:2119-2124.

33 Weng AP, Ferrando AA, Lee W, Morris JP 4th, Silverman LB, Sanchez-Irizarry C, Blacklow SC, Look AT, Aster JC: Activating mutations of Notch1 in human T cell acute lymphoblastic leukemia. Science 2004;306: 269-271.
4 O'Neil J, Calvo J, McKenna K, Krishnamoorthy V, Aster JC, Bassing CH, Alt FW, Kelliher M, Look AT: Activating Notch1 mutations in mouse models of T-ALL. Blood 2006;107: 781-785.

35 Paganin M, Ferrando A: Molecular pathogenesis and targeted therapies for Notch1induced T-cell acute lymphoblastic leukemia. Blood Rev 2011;25:83-90.

36 Shin HM, Minter LM, Cho OH, Gottipati S, Fauq AH, Golde TE, Sonenshein GE, Osborne BA: Notch1 augments NF- $\kappa \mathrm{B}$ activity by facilitating its nuclear retention. EMBO J 2006;25:129-138.

37 Vilimas T, Mascarenhas J, Palomero T, Mandal M, Buonamici S, Meng F, Thompson B, Spaulding C, Macaroun S, Alegre ML,Kee BL, Ferrando A, Miele L, Aifantis I: Targeting the NF- $\mathrm{KB}$ signaling pathway in Notch1induced T-cell leukemia. Nat Med 2007;13: 70-77.

38 Espinosa L, Cathelin S, D’Altri T, Trimarchi T, Statnikov A, Guiu J, Rodilla V, Inglés-Esteve J, Nomdedeu J, Bellosillo B, Besses C, Abdel-Wahab O, Kucine N, Sun SC, Song G, Mullighan CC, Levine RL, Rajewsky K, Aifantis I, Bigas A: The Notch/Hes1 pathway sustains NF- $\mathrm{KB}$ activation through CYLD repression in $\mathrm{T}$ cell leukemia. Cancer Cell 2010;18:268-281.

39 Shin DY, Kim I, Kim KH, Choi Y, Beom SH, Yang Y, Lim Y, Lee E, Lee JK, Kim JY, Kim HK, Yoon SS, Lee DS, Park S, Kim BK: Acute lymphoblastic leukemia in elderly patients: a single institution's experience. Korean J Intern Med 2011;26:328-339.

40 Schlieben S, Borkhardt A, Reinisch I, Ritterbach J, Janssen JW, Ratei R, Schrappe M, Repp R, Zimmermann M, Kabisch H, JankaSchaub G, Bartram CR, Ludwig WD, Riehm H, Lampert F, Harbott J: Incidence and clinical outcome of children with BCR/ABLpositive acute lymphoblastic leukemia (ALL). A prospective RT-PCR study based on 673 patients enrolled in the German pediatric multicenter therapy trials ALL-BFM-90 and CoALL-05-92. Leukemia 1996;10:957963.

41 Jagani Z, Singh A, Khosravi-Far R: FoxO tumor suppressors and BCR-ABL-induced leukemia: a matter of evasion of apoptosis. Biochim Biophys Acta 2008;1785:63-84.
42 Jagani Z, Song K, Kutok JL, Dewar MR, Melet A, Santos T, Grassian A, Ghaffari S, Wu C, Yeckes-Rodin H, Ren R, Miller K, Khosravi-Far R: Proteasome inhibition causes regression of leukemia and abrogates BCRABL-induced evasion of apoptosis in part through regulation of forkhead tumor suppressors. Cancer Res 2009;69:6546-6555.

-43 Dewar R, Chen ST, Yeckes-Rodin H, Miller K, Khosravi-Far R: Bortezomib treatment causes remission in a $\mathrm{Ph}+\mathrm{ALL}$ patient and reveals FoxO as a theranostic marker. Cancer Biol Ther 2011;11:552-558.

44 Hideshima T, Mitsiades C, Akiyama M, Hayashi T, Chauhan D, Richardson P, Schlossman R, Podar K, Munshi NC, Mitsiades N, Anderson KC: Molecular mechanisms mediating antimyeloma activity of proteasome inhibitor PS-341. Blood 2003;101: 1530-1534.

-45 Lin A, Dibling B: The true face of JNK activation in apoptosis. Aging Cell 2002;1:112-116.

46 Verma G, Datta M: The critical role of JNK in the ER-mitochondrial crosstalk during apoptotic cell death. J Cell Physiol 2012;227: 1791-1795.

47 Luo P, Lin M, Li L, Yang B, He Q: The proteasome inhibitor bortezomib enhances ATRA-induced differentiation of neuroblastoma cells via the JNK mitogen-activated protein kinase pathway. PLoS One 2011; 6:e27298.

48 Dasmahapatra G, Lembersky D, Rahmani M, Kramer L, Friedberg J, Fisher RI, Dent P, Grant S: Bcl-2 antagonists interact synergistically with bortezomib in DLBCL cells in association with JNK activation and induction of ER stress. Cancer Biol Ther 2009;8:808819 .

49 Kang MH, Wan Z, Kang YH, Sposto R, Reynolds CP: Mechanism of synergy of N -(4-hydroxyphenyl) retinamide and ABT737 in acute lymphoblastic leukemia cell lines: Mcl-1 inactivation. J Natl Cancer Inst 2008;100:580-595.

50 Saunders P, Cisterne A, Weiss J, Bradstock $\mathrm{KF}$, Bendall LJ: The mammalian target of rapamycin inhibitor RAD001 (everolimus) synergizes with chemotherapeutic agents, ionizing radiation and proteasome inhibitors in pre-B acute lymphocytic leukemia. Haematologica 2011;96:69-77. 